LINGUA, Vol. 14, No. 2, September 2017

p ISSN: 1979 9411; e ISSN: 2442 238X

Http://lingua.pusatbahasa.or.id; Email: presslingua@gmail.com

Center of Language and Culture Studies, Surakarta, Indonesia

Pehala, Askul Ilfan. 2017. Frase dan Klausa dalam

Kata Polisintesis pada Bahasa Tolaki. Lingua (2017), 14(2): 127 140.

\title{
FRASA DAN KLAUSA DALAM KATA POLISINTESIS PADA BAHASA TOLAKI
}

\author{
Ilfan Askul Pehala \\ Program Magister Linguistik, Universitas Sebelas Maret \\ Jl. Ir. Sutami 36A Kentingan, Surakarta \\ Email: faizsaniyasnaini@gmail.com
}

\begin{abstract}
This study examines the descriptions of phrases and sentences in the polysynthesis words. Sources of data of this study polyshyntesis words in Tolaki Language. Data were collected using observation and interview. Data were anlyzed using descriptive qualitative of formal and informal techniques. The study revealed that: (1) construction of phrases and sentences in the polyshyntesis words, (2) kinds of phrases in the polyshinthesis words, (3) functions, roles, and categories of clauses in the polysunthesis words, and (4) polysinthesis occured due to lapses or changes of mofphology of the Tolaki speakers.
\end{abstract}

Keywords: polysynthetic words, phrase, clause, role, category.

Bahasa-bahasa yang ada di dunia secara tidak sadar atau tidak telah berada dalam lingkaran pentipean atau tipologisasi dan ini penting dilakukan untuk menemukan keunikan atau ciri-ciri pembeda dengan bahasa lain. Dalam tipologi bahasa, linguistic yang merupakan ilmu dengan pembagian sub-keilmuannya ditujukan untuk melakukan pengelompokkan bahasa dan pembedaan bahasa berdasarkan fakta dan data bahasa yang ada di lapangan utamanya data verbal dari para native speaker, menghubungkan unsur bahasa dan mengendalikan atau mengkaji secara mendalam gejala atau fenomena bahasa yang ada secara ilmiah (lihat Parera, 1991:5). Diantara bahasa yang ada di dunia khususnya di Indonesia yang menjadi kajian dalam makalah ini adalah bahasa Tolaki yang dituturkan oleh masyarakat Suku Tolaki yang ada di wilayah Sulawesi Tenggara yang tersebar di Konawe dan Kota Kendari, Konawe Utara, Konawe Selatan, Kolaka dan sekitarnya dan wilayah lainnya yang menuturkan bahasa Tolaki yang masuk dalam rumpun Austronesia dan memiliki kekhasan sebagai bahasa vokalis dan penuturnya yang pada umumnya memiliki kulit kuning langsat atau putih dan berwajah oriental.

Penelitian mengenai gramatika ataupun kaidah bahasa Tolaki sebelumnya pernah dilakukan oleh Owen Edwards (2012) yang berjudul "Grammatical Functions in Tolaki" dimana penelitian ini menyimpulkan mengenai unsur-unsur konstituen dalam bahasa Tolaki. Selain dari bahasa Tolaki, ada juga penelitian yang dilakukan oleh Ernawati Br Surbakti (2012) yang berjudul "Tipologi Sintaksis Bahasa Karo" dimana penelitian ini ini menyimpulkan bahwa tipologi 
LINGUA, Vol. 14, No. 2, September 2017

p ISSN: 1979 9411; e ISSN: 2442 238X

Http://lingua.pusatbahasa.or.id; Email: presslingua@gmail.com

Center of Language and Culture Studies, Surakarta, Indonesia

Pehala, Askul Ilfan. 2017. Frase dan Klausa dalam

Kata Polisintesis pada Bahasa Tolaki. Lingua (2017), 14(2): 127 140.

sintaksis bahasa Karo adalah tipe VSO/PSO karena bahasa Karo umumnya kalimat pasif yang $\mathrm{P}$ berada di awal kalimat dan subjeknya adalah kata benda dan diikuti oleh SVO/SPO. Kedua penelitian ini memang mengkaji kaidah sintaksis bahasa, namun belum menjelaskan polisintesis yang memiliki fungsi frasa dan klausa dalam bahasa. Sehingga polisintesis merupakan suatu objek penelitian yang dapat ditelusuri lebih mendalam berdasarkan unsur pembentuk kata itu sendiri.

Penelitian ini difokuskan pada analisis secara morfosintaksis terhadap kata-kata polisintesis yang banyak terdapat dalam percakapan atau penulisan sehari-hari, yakni frasa dan kalimat yang sering terdapat dalam kata berpolisintesis. Dalam melakukan analisa kajian terfokus pada, pertama yakni konstruksi frasa dan kalimat dalam kata polisintesis untuk mengetahui unsurunsur konstituen pembangunnya. Kedua, jenis frasa yang terdapat dalam kata polisintesis dikarenakan ada kecenderungan polisintesis juga memiliki fungsi frasal. Ketiga, fungsi, peran dan kategori klausa yang terdapat dalam kata polisintesis. Meski hal ini adalah kontroversial bagi sebagian pembaca, namun penulis berpendapat bahwa di dalam polisintesis fungsi, peran dan kategori diisi oleh morfem-morfem konstituen kata itu sendiri. Terakhir adalah faktor-faktor yang menyebabkan polisintesis itu terjadi padahal bahasa ini merupakan bahasa aglutinatif dan bukan bahasa inkorporatif yang umumnya dalam konstruksi sintaksis bahasanya adalah polisintesis. Dengan melakukan analisis terhadap polisintesis, maka keunikan dari kata ini bisa dikaji berdasarkan unsur konstituennya.

Dalam bahasa, fenomena polisintesis merupakan hal yang sering terjadi dalam percakapan atau penulisan kalimat bahasa. Meskipun bahasa aglutinatif yang menggunakan afiksisasi dalam proses pembentukan kata-kata di dalamnya, namun kenyataannya polisintesis banyak ditemukan dalam pola kalimat, klausa ataupun frasa. Kridalaksana (1982:65) menyatakan bahwa inkorporasi adalah pemaduan morfem-morfem dasar menjadi kata tunggal, sedangkan Keraf (1990:62-63) menjelaskan bahwa inkorporatif disamakan dengan polisintesis. Polisintesis mengacu pada sebuah bahasa yang menggabungkan sejumlah besar morfem, baik leksikal maupun gramatikal menjadi sebuah kata dan sering dihubungkan dengan sebuah kalimat. Selain itu, bahasa inkorporatif menggabungkan sebuah kata kerja, subjek, objek dan bermacam-macam menjadi sebuah kata.

Berdasarkan definisi di atas, maka disimpulkan bahwa bahasa polisintesis atau inkorporatif mestilah bahasa yang secara tulisan (tulisan adalah wujud abstrak yang dapat diamati secara cermat dan visual) pastilah kata dan satuan lingual seperti frasa dan kalimat adalah kata. Bahasa inkorporatif biasanya ditemukan pada bahasa Eskimo Yupi di Siberia dan bahasa Yana, Indian Amerika, bahasa Greenlandik dan bahasa lainnya. Namun kenyataannya, banyak bahasa yang merupakan bahasa aglutinatif, namun ada kecenderungan bahasa ini juga inkorporatif namun tidak semuanya harus polisintesis. Polisintesis pada bahasa-bahasa ini selalunya melalui proses morfologis dimana ada pelesapan pada 
kata-kata yang kebanyakan adalah pronomina subjek, objek ataupun lainnya menjadi morfem imbuhan akhir atau sufiks. Bukan hanya itu saja, polisintesis ada juga yang membentuk frasa meskipun secara struktur, frasa ini adalah kata.

Mengenai frasa, Kridalaksana (1982:46) mendefinisikan frasa sebagai gabungan dua kata atau lebih yang sifatnya tidak predikatif. Beberapa sumber lainnya memiliki pandangan yang sama dimana frasa adalah satuan lingual yang memiliki inti/head dan modifier ataupun complements (lihat Sportiche, Koopman, dan Stabler (2014); Carnie (2002); dan Matthews (1981)). Mathews (1981:161162) menjelaskan bahwa konstruksi sebuah frasa dapat ditetapkan seperti satu konstruksi yang memiliki inti dan sebuah frasa sebagai satu unit yang berperan seperti sebuah konstruksi. Sebuah 'frasa A' (atau 'A-(i)al' secara rinci merupakan sebuah frasa yang inti dari konstruksinya adalah 'A'.

Namun pada beberapa frasa terkadang apa yang diasumsikan menjadi head bukanlah head di dalam frasa itu sendiri. Ini bisa dilihat pada frasa determiner dan frasa preposisional dimana head pada frasa ini bukanlah determiner ataupun preposisi namun yang menjadi head adalah frasa nominal. Ini disebabkan determiner ataupun preposisi berperan sebagai complement dan modifier saja. Selain itu kelas kata yang menjadi 'ciri' dari frasa itu sendiri bukanlah dari open class categories seperti nomina, verba, ajektiva dan adverbia. Namun 'ciri' dari frasa ini dari close class categories seperti preposisi, determiner, numeral, complementizers, kata kerja bantu, modals, coordinator dan negasi/afirmasi (Sportiche, Koopman, dan Stabler (2014:10).

Ini berbeda dengan frasa yang 'ciri'-nya dari open class categories seperti nomina, verba, ajektiva dan adverbia; yang terdapat pada frasa verba, frasa nomina, frasa ajektiva dan frasa adverbia dimana inti/head-nya adalah nomina, verba, ajektiva dan adverbia dan close class categories seperti preposisi, determiner (berupa articles, demonstratives dan quantifiers), numeral, complementizers, kata kerja bantu, modals, coordinator dan negasi/afirmasi adalah modifier ataupun complemets. Sportiche, Koopman, dan Stabler (2014: 105-119) dan membagi frasa menjadi lima jenis frasa tanpa frasa adverbial yaitu verb phrases (VP), determiner phrases (DP), noun phrases (NP), adjective phrases (Adj. P), dan prepositional phrases (Prep. P); dan Carnie (2002:144) juga menjelaskan mengenai determiner phrases. Sedangkan pada beberapa sumber lainnya seperti Matthews (1981) dan Kridalaksana (1982) frasa adverbial disebutkan namun tidak menyebutkan adanya frasa determiner misalnya Kridalaksana (1982:46) mendefinisikan frasa adverbial dimana adverbia sebagai induk dan adverbia lain sebagai modifikator atau ppenelitian.

Klausa adalah satuan gramatikal berupa kelompok kata yang sekurangkurangnya terdiri dari subjek dan predikat dan mempunyai potensi untuk menjadi kalimat (Kridalaksana, 1982:85). Kalimat merupakan satuan bahasa yang secara relatif berdiri sendiri, mempunyai pola intonasi final yang secara aktual maupun potensial terdiri dari klausa (Kridalaksana, 1982:71).

Dalam menganalisis kalimat, sangatlah penting untuk melihat fungsi, peran, dan kategori. Di mana ini dapat digunakan dalam membantu menganalisis 
LINGUA, Vol. 14, No. 2, September 2017

p ISSN: 1979 9411; e ISSN: 2442 238X

Http://lingua.pusatbahasa.or.id; Email: presslingua@gmail.com

Center of Language and Culture Studies, Surakarta, Indonesia

Pehala, Askul Ilfan. 2017. Frase dan Klausa dalam

Kata Polisintesis pada Bahasa Tolaki. Lingua (2017), 14(2): 127 140.

kalimat berdasarkan unsur-unsur konstituen pembangun kalimat itu sendiri. Kridalaksana, (1982:48) menjelaskan bahwa fungsi merupakan peran sebuah unsur dalam satuan sintaksis yang lebih luas; misalnya nomina yang berfungsi sebagai subjek atau objek. Untuk peran Putrayasa, (2014:13) menjelaskan bahwa peran mengisi unsur fungsional yang berkaitan dengan makna gramatikal yang berupa pelaku, perbuatan, sasaran, dan tempat. Sedangkan untuk kategori Kridalaksana, (1982:78) menyebutkan bahwa kategori di sini merupakan satuan bahasa yang dibedakan atas bentuk fungsi dan makna seperti kelas kata, jenis, kasus, kata, dan sebagainya. Putrayasa, (2014:13) menyebutkan bahwa kategori berupa frasa dan kelas kata seperti nominal, verbal, preposisi, dan lain-lain.

\section{METODE}

Dalam penelitian ini, metode yang adalah metode kualitatif dengan teknik simak dan catat. Dikatakan sebagai penelitian kualitatif baik data maupun hasil yang diperoleh dalam penelitian ini adalah data verbal yang berupa frasa dan kalimat yang berwujud kata berpolisintesis yang ada dalam bahasa Tolaki dan Sasak. Oleh karena itu, teknik pengumpulan data yang digunakan penelitian ini adalah metode simak dan catat dengan teknik rekam dan teknik pembacaan dan teknik pencatatan atau catat. Data dalam penelitian ini adalah kata yang memiliki bentuk polisintesis yang mengandung fungsi frasa dan kalimat yang terdapat bahasa Tolaki dan Sasak. Sumber data berasal dari tuturan yang digunakan oleh penutur asli dalam percakapan sehari-hari

Objek penelitian ini adalah kata berpolisintesis yang berfungsi sebagai frasa dan kalimat. Penelitian ini difokuskan pada frasa dan kalimat yang terdapat di dalam bahasa Tolaki dan Sasak. Penelitian ini juga memfokuskan fungsi, peran dan kategori yang ada pada kata berpolisintesis pada kedua bahasa tersebut. Teknik analisis data yang digunakan dalam penelitian ini adalah teknik deskriptif kualitatif. Teknik ini digunakan mengingat data-data dalam penelitian ini berupa data verbal yang memerlukan penjelasan secara deskriptif yang disajikan secara formal dan informal. Selain itu, data juga dianalisis dengan menggunakan Metode padan dalam Sudaryanto (1993:13) diartikan sebagai alat penentunya di luar, terlepas, dan tidak menjadi bagian dari bahasa (langue) yang bersangkutan. Dalam metode padan ini dapat dibedakan menjadi lima macam bentuknya yaitu, (1) alat penentunya ialah kenyataan yang ditunjuk oleh bahasa atau referent bahasa; (2) alat penentunya organ pembentuk bahasa atau organ wicara, $(3,4,5)$ berturut-turut adalah adalah bahasa lain atau langue lain, perekam dan pengawet bahasa (yaitu tulisan), serta orang yang menjadi mitra wicara.

Teknik yang digunakan dalam analisis padan ini adalah teknik Pilah Unsur Tertentu (PUP). Teknik ini alatnya adalah daya pilah yang bersifat mental yang dimiliki oleh penelitinya. Sesuai dengan jenis penentu yang akan dipilah-pilahkan atau dipisah-pisahkan atau dibagi menjadi beberapa unsur itu maka daya pilah itu dapat disebut " dayah pilah referensial", "daya pilah artikulatoris", "daya pilah translasional", "daya pilah ortografis", dan "daya pilah pragmatis". Adapun dasar 
pembagiannya atau dasar pemilahan sudah barang tentu disesuaikan dengan sifat atau watak penentu itu masing-masing.

\section{HASIL DAN BAHASAN}

Polisintesis pada bahasa Tolaki selalunya melalui proses morfologis dimana ada pelesapan pada kata-kata yang kebanyakan adalah pronomina subjek, objek ataupun lainnya menjadi morfem imbuhan akhir atau sufiks. Misalnya pronomina inaku (saya) mengalami perubahan menjadi $a k u$ atau $k u$ - untuk subjek dan -nggu sebagai genitive. Sementara pronominal inggomiu ${ }^{l}$ (kamu) mengalami perubahan menjadi -miu sebagai objek dan genitive. Pronomina kamu selain inggomiu ada juga inggo' $o^{2}$ yang juga mengalami perubahan menjadi -mu sebagai objek dan genitive.

Berikut adalah contoh polisintesis yang ada pada bahasa Tolaki

\section{Ku'eheko $=K u$-ehe-ko Ku'eheko 'saya-menyukai-kamu'}

Kata Ku'eheko bila dilihat secara asal kata atau unsur kata dan adanya pelesapan pada sebagian fonem-fonem pada kata yakni inaku mengalami pelesapan pada ina dan $k u$ tetap dipertahankan untuk mempertahankan unsur bentuk 'saya'. Kemudian umehe mengalami perubahan atau pelesapan pada ume dan he tetap dipertahankan untuk identitas verba 'menyukai' dan inggo'o mengalami perubahan atau pelesapan ing dan go'o menjadi ' $k o$ '. Kalimat di atas merupakan tipe kalimat yang sederhana sehingga ini merupakan dasar awal kita dalam melihat polisintesis.

2. Kulangguko aupenasa'i teembe mohakino penaonggu 'saya memukul kamu agar kamu merasakan betapa sakitnya hatiku'

$$
\begin{aligned}
& \text { ku-langgu-ko= 'saya memukul kamu' } \\
& \text { au-penasa-' } i=\text { 'kamu merasakan itu' } \\
& \text { teembe = 'bagaimana' } \\
& \text { mohaki-no = 'sakit-nya' } \\
& \text { penao-nggu = 'nafas/hati-ku' }
\end{aligned}
$$

Kalimat di atas bila dilihat terdiri atas 5 kata yang dilihat secara struktur adalah tersusun dari 2 klausa, 2 frasa dan 1 kata. Bila disegmentasi secara cermat berdasarkan morfem-morfem penyusun pada kata yang adalah klausa dan frasa, maka kita dapat melihat bahwa Kulangguko tersusun dari inaku-langgu-inggo'o dan aupenasa'i tersusun dari Inggo'o (yang berubah menjadi au) au-penasainggitu. Sedangkan untuk frasa, mohakino tersusun dari Mohaki-inono (ini) dan penaonggu yang tersusun dari penao-inaku (yang berubah menjadi -nggu). Maka dapat kita lihat bahwa morfem-morfem dasar atau kata pada polisintesis yang ada

\footnotetext{
1 Inggomiu digunakan pada orang yang dihormati, orang yang lebih tua ataupun statusnya di atas penutur.

2 Inggo'o digunakan pada orang yang setara atapun di bawah penutur
} 
pada contoh kalimat (2) mengalami perubahan menjadi morfem terikat dalam susunan pada kata yang merupakan klausa atau kalimat dan frasa.

3. Inggitu o'ika kurako'i mombake obaki

'ikan itu aku tangkap dengan menggunakan keranjang rotan'

* Inggitu = itu,

* o’ika $\rightarrow o=$ penanda nomina atau determiner definit, $i k a=$ ikan

* $k u-r a k o-i \rightarrow$ inaku $=$ saya, rako $=$ tangkap, inggitu $=\mathrm{itu}$

* mombake = memakai

* obaki $\rightarrow o=$ penanda nomina/determiner definit, baki $=$ keranjang rotan

Pada kalimat (3), terlihat polisintesis hanya ada 1 saja yakni pada kata kurako'i 'aku tangkap itu' dan selebihnya merupakan kata-kata yang terdiri atas nomina dan verba serta demonstrative. Maka terlihat dengan jelas bahwa polisintesis memiliki pola atau situasi tertentu dan tidak digunakan pada semua momen.

Kalimat (1), (2) dan (3) merupakan contoh polisintesis yang digunakan dalam pola kalimat dalam penggunaan sehari-hari. Untuk yang lainnya, berikut adalah kata-kata yang diindikasikan masuk ke dalam polisintesis, yakni sebagai berikut:

kutobo' $i$ 'saya menikamnya'

- $k u-$ tobo-I $\rightarrow k u-($ inaku $)=$ saya, tobo $=$ tikam, $-i\left(\boldsymbol{i} e^{3}\right)=$ dia ('lk/pr')

kukeketako 'aku (akan) mengigit kamu'

- $k u$-keketa-ko $\rightarrow k u$ - $($ inaku $)=$ saya, keketa = gigit, $-k o$ (ing god $\mathbf{0})=\mathrm{kamu}$

ku'uma'i 'saya mencium dia'

- $k u-u m a-i \rightarrow k u-($ inaku $)=$ saya, uma $=\operatorname{cium},-i(\boldsymbol{i} e)=$ dia ('lk/pr')

$>$ notinggiko 'dia menjitak kamu'

- $\quad$ no-tinggi-ko $\rightarrow$ no (penanda dia ' $\mathrm{lk} / \mathrm{pr}$ '), tinggi $=\mathrm{jitak}, \quad-k o$ (ing god $\mathbf{0})=\mathrm{kamu}$

aro'aleko 'mereka nanti mengambil/menculik kamu'

- aro-ale-ko $\rightarrow$ aro $^{4}$ (penanda mereka ' $\mathrm{lk} / \mathrm{pr}$ '), ale = mengambil, $-k o($ ing $\mathbf{g o} \mathbf{0})=$ kamu

rorakoko 'mereka menangkap kamu'

\footnotetext{
${ }^{3}$ Ie pada bahasa Tolaki bisa berarti 'ya' atau 'dia'. Penulisan ie terkadang menggunakan 'ie' atau 'iye'. Tapi penulis lebih merujuk pada ' $i e$ ' dengan fonetis [Iye]

${ }^{4}$ Aro dalam pengamatan penulis melekat pada pronomina ' $r o$ ' = 'mereka' dan aspek modal 'akan, nanti' biasanya melekat pada kata ini secara bersamaan
} 
LINGUA, Vol. 14, No. 2, September 2017

p ISSN: 1979 9411; e ISSN: 2442 238X

Http://lingua.pusatbahasa.or.id; Email: presslingua@gmail.com

Center of Language and Culture Studies, Surakarta, Indonesia

Pehala, Askul Ilfan. 2017. Frase dan Klausa dalam

Kata Polisintesis pada Bahasa Tolaki. Lingua (2017), 14(2): 127 140.

- ro-rako-ko $\rightarrow$ ro $($ ihiro $)=$ mereka, rako $=$ tangkap, $-k o$ (ing godo $)=$ kamu

akutolako 'saya akan pergi'

- $a k u$-to-lako $\rightarrow$ ku- (inaku $)=$ saya, to (penanda akan), lako = pergi

ketotinidu 'mereka akan dipukul'

- $k e$-to-tinidu $\rightarrow$ ke (penanda mereka ${ }^{5}$ ), to (penanda akan), tinidu $^{6}=$ ditinju.

rotanggudu' $i$ 'mereka menjitaknya'

- ro-tanggudu-'i $\rightarrow$ ro (ihiro) $=$ mereka, tanggudu $=$ menjitak, $-i(\boldsymbol{i} e)=\operatorname{dia}\left({ }^{\prime} \mathrm{lk} / \mathrm{pr}\right.$ ')

Polisintesis pada bahasa Tolaki memanglah ada dan tidak dipungkiri sering terjadi dalam percakapan atau penulisan sehari-hari dimana polisintesis tersebut memiliki pola S P seperti akutolako 'saya akan pergi', akulako 'saya pergi', kulako 'saya pergi', P O seperti uma' $i$ 'cium dia' dan S P O seperti kutobo' $i$ 'saya menikam dia'. Namun, tidak semua hal bisa dipolisintesis karena kata-kata juga pada bahasa Tolaki bisa berdiri sendiri baik yang dasar atau kata yang memiliki unsur imbuhan. Selain itu, kalimat atau ujaran pada bahasa Tolaki banyak yang tersusun dari kata-kata dan frasa seperti bahasa aglutinatif ${ }^{7}$ pada umumnya dan polisintesis pada umumnya adalah kata meskipun bila disegmentasi merupakan klausa.

Suatu hal yang bukan kebetulan bila bahasa Tolaki memiliki kata yang disegmentasi merupakan klausa berdasarkan ciri-ciri bahasa inkorporatif ${ }^{8}$ seperti penjelasan Keraf (1990). Meskipun bahasa Tolaki adalah bahasa aglutinatif atau bahasa berafiks, namun polisintesis dapat ditemukan dalam lisan ataupun tulis. Penulis melihat ada beberapa faktor yang menjadi hipotesis mengapa polisintesis pada bahasa Tolaki dimana itu terlihat dengan adanya kecenderungan para penutur dalam melakukan pelesapan dan perubahan yang umumnya adalah morfemis adalah untuk perimbangan atau efisiensi dalam bertutur sehingga lidah mereka tidak mengeluarkan tuturan secara bertele-tele. Ini dapat dilihat pada pronomina 'inaku' yang menjadi ' $k u$-' atau ' $a k u$ ' sebagai subjek, 'aku' sebagai objek' misalnya dalam kata keketa'aku 'gigit saya', ie menjadi -i untuk dia sebagai subjek dan menjadi penanda dan lainnya.

Sejauh ini, penulis melihat bahwa pelesapan serta perubahan yang dilakukan pada umumnya dan kebanyakan terjadi pada pronomina baik dalam

\footnotetext{
${ }^{5}$ Pronomina 'mereka' dalam bahasa Tolaki adalah 'ihiro'

${ }^{6}$ bentuk dasarnya adalah 'tidu', dengan infiks '-ni-' maka akan menghasilkan verba pasif

${ }^{7}$ Bahasa yang dapat menambahkan unsur-unsur afiks pada akar katanya, seperti: sufiks, prefix, infiks, konfiks tanpa mengalami fusi. Bahasa-bahasa aglutinatif di satu pihak dapat dibagi-bagi atas bahasa yang memiliki prefix saja, yang memiliki infiks, dan yang memiliki sufiks saja atau campuran dari dua atau tiga afiks tersebut (Keraf, 1990: 83)

${ }^{8}$ Polisintesis mengacu pada sebuah bahasa yang menggabungkan sejumlah besar morfem, baik leksikal maupun gramatikal menjadi sebuah kata dan sering dihubungkan dengan sebuah kalimat. Selain itu, bahasa inkorporatif menggabungkan sebuah kata kerja, subjek, objek dan bermacam-macam menjadi sebuah kata (Keraf, 1990: 62-63)
} 
posisi subjek, objek atau genitive. Sementara verba, aspek dan lainnya melekat pada pronomina ataupun terpisah. Maka penulis berasumsi bahwa pelesapan serta perubahan hanya terjadi pada pronominal saja. Contoh pronominal yang dimaksudkan adalah sebagai berikut:

- Inaku 'saya' = subjek $\rightarrow$ ' $k u$ - ' atau ' $a k u$ ' sebagai subjek, ' $a k u$ ' sebagai objek dan '-nggu' sebagai genitive atau penanda posesif ajektif. Ihiro 'mereka' = subjek mengalami perubahan secara morfemis menjadi 'ro' = subjek ataupun objek.

Contoh kalimatnya adalah sebagai berikut:

a. Kalimat nominal

-Mohakinggu 'saya merasa sakit'

-Inaku me'ita 'saya tinggi'

-Kulaa meohaki 'saya-sedang sakit'

-Inaku inono gurumu 'saya ini adalah guru-mu'

-Ku-laa ilaikamu 'saya-sedang berada di rumah-mu'

b. Kalimat verbal

-Kupodea'ika hawo laa sinarumu ihawi = Ku-podea'i-ka hawo laa sinaru-mu ihawi 'saya mendengar-(juga) apa yang sedang kamu ucapkan kemarin'

-Teembeto bawomiu, naina? = Teembe-to bawomiu, naina? 'bagaimana-(kah) kabar anda, Bu'

-Nopetiso ikita = No-petiso ikita 'dia-menunjuk di sana'

-Rolaa mololesi kaluku ano tealo kapala lumaaro = Ro-laa mololesi kaluku ano tealo kapala lumaa-ro 'merekasedang mengupas kelapa saat/kemudian lewat pesawat terbang-mereka

Mengenai fungsi, peran dan kategori; kalimat yang ada pada kata berpolisintesis pada bahasa Tolaki. Polisintesis terjadi biasanya dalam kata yang berpola kalimat S-P-O, S-P, dan P-O. di dalam kata tersebut terkadang ada juga hanya subjek yang melekat dengan aspek modal atau kata kerja bantu ataupun penanda kala atau tense atau dengan pola $S+$ aspek modal/penanda kala atau tense. Sejauh ini, penulis mengamati bahwa polisintesis hanya terjadi pada pronomina saja yang dilekatkan dengan verba baik sebagai subjek dan objek. Akan tetapi, bila subjek melekat dengan aspek, maka verbanya akan terpisah dan melekat pada objek yang secara otomotatis menjadi klausa dengan pola $\mathrm{P}$ O. Sedangkan untuk peran yang terdapat dalam kata polisintesis, ada yang berperan sebagai aktor/agen/pelaku, tindakan/act dan pasien atau sasaran. Sedangkan untuk kategori, morfem-morfem terikat atau lebih tepatnya unsur terikat bisa dilihat melalui unsur bebas sebagai morfem dasar pembentukan kata yang memiliki fungsi kalimat atau frasa dan unsur terikat yang melekat pada unsur bebas. Dalam 
contoh-contoh di atas ada kecenderungan bahwa unsur bebasnya adalah berkategori verba yang berperan sebagai tindakan dan memiliki fungsi sebagai predikat. Sedangkan unsur terikatnya adalah berkategori nomina yang memiliki fungsi sebagai subjek dan objek, peran sebagai pelaku dan sasaran.

Hal ini dapat dilihat melalui analisis konstruksi pada unsur konstituen pembentuk kata yang mengindikasikan klausa, yakni sebagai berikut dengan salah satu contoh kata kueheko = ku-ehe-ko 'saya menyukai kamu':
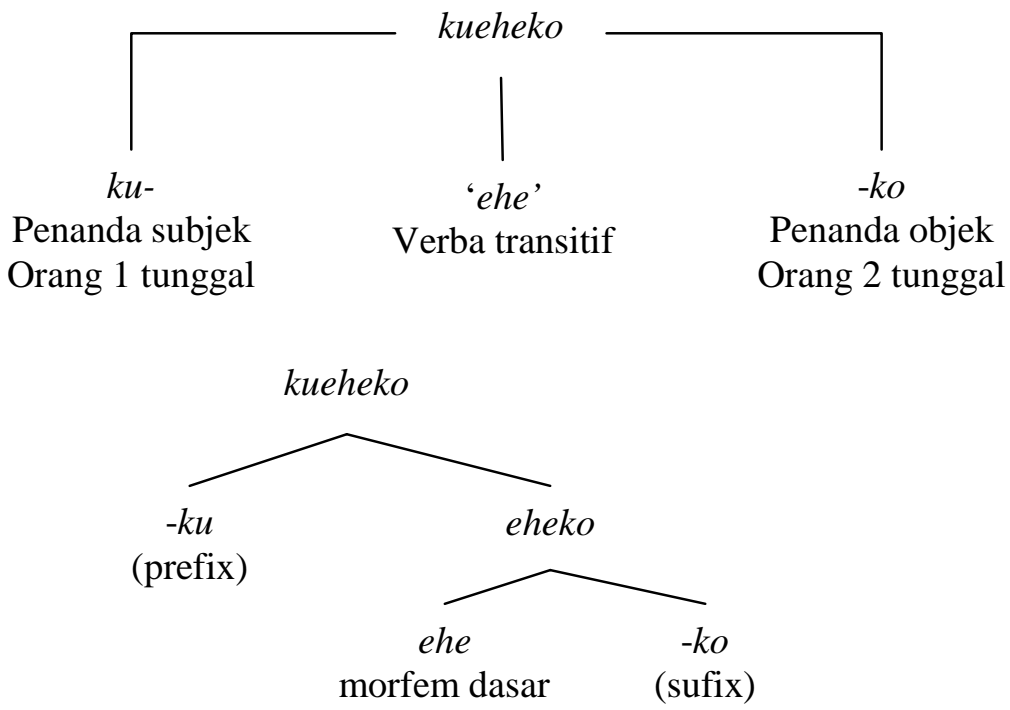

Gambar 1. Konstruksi klausa dan frasa dalam kata polisintesis berdasarkan konstituen morfem penyusun kata

Perubahan dan pelesapan itu hanya menyisakan fonem ataupun morfem yang menjadi penanda utamanya subjek dan melekat pada verba ataupun objek atau genitif. Penulis memiliki hipotesis bahwa fonem atau morfem yang ada sekarang dan menjadi penanda subjek, objek dan genitive memiliki 'sejarah' yang memiliki jejak tersisa dan sisanya menjadi penanda pronomina yang melekat pada verba atau nomina. Fonem atau morfem yang merupakan hasil pelesapan menjadi penanda pronomina dalam posisi subjek, objek atau genitive. Pronomina itu ada yang dari Pronomina persona 1, 2 dan 3 dari tunggal atau jamak. 
Tabel 1. Konstruksi Fungsi, peran dan kategori pada klausa dalam kata polisintesis berdasarkan morfem penyusun kata

\begin{tabular}{|c|c|c|c|c|c|}
\hline \multirow[b]{2}{*}{ Kalimat } & \multirow[b]{2}{*}{ Kata } & \multirow{3}{*}{ * } & \multicolumn{3}{|c|}{ Berdasarkan posisi morfem dalam kata } \\
\hline & & & $\begin{array}{c}\text { Fungsi } \\
\left(\mathbf{F}^{*}\right)\end{array}$ & $\begin{array}{c}\text { Peran } \\
\left(\mathbf{P}^{*}\right)\end{array}$ & $\begin{array}{c}\text { Kategori } \\
\left(\mathbf{K}^{*}\right)\end{array}$ \\
\hline \multirow{4}{*}{$\begin{array}{l}\text { Aku membaca } \\
\text { (buku/kitab) } \\
\text { itu }\end{array}$} & \multirow{4}{*}{ Kubasa'i } & & $k u-$ & basa & $-i$ \\
\hline & & $\mathbf{F}$ & $\begin{array}{l}\text { Penanda } \\
\text { Subjek }\end{array}$ & Predikat & $\begin{array}{l}\text { Penanda } \\
\text { objek }\end{array}$ \\
\hline & & $\mathbf{P}$ & Pelaku/actor & Tindakan & $\begin{array}{l}\text { Pasien/sasara } \\
\mathrm{n}\end{array}$ \\
\hline & & $\mathbf{K}$ & Nomina & verba & Nomina \\
\hline \multirow{4}{*}{$\begin{array}{l}\text { Aku } \\
\text { melepaskan } \\
\text { (sesuatu) } \\
\text { kepadanya }\end{array}$} & \multirow{4}{*}{$\begin{array}{l}\text { Kupobindak } \\
e\end{array}$} & * & $k u-$ & pobinda & $-k e$ \\
\hline & & $\mathbf{F}$ & $\begin{array}{l}\text { Penanda } \\
\text { Subjek }\end{array}$ & Predikat & $\begin{array}{l}\text { Penanda } \\
\text { objek }\end{array}$ \\
\hline & & $\mathbf{P}$ & Pelaku/actor & Tindakan & $\begin{array}{l}\text { Pasien/sasara } \\
\mathrm{n}\end{array}$ \\
\hline & & $\mathbf{K}$ & Nomina & verba & Nomina \\
\hline \multirow{4}{*}{$\begin{array}{l}\text { Aku melepas } \\
\text { (sesuatu) }\end{array}$} & \multirow{4}{*}{ kupobinda } & $*$ & $k u-$ & pobinda & \\
\hline & & $\mathbf{F}$ & $\begin{array}{l}\text { Penanda } \\
\text { Subjek }\end{array}$ & Predikat & $\begin{array}{l}\text { Penanda } \\
\text { objek }\end{array}$ \\
\hline & & $\mathbf{P}$ & Pelaku/actor & Tindakan & $\begin{array}{l}\text { Pasien/sasara } \\
\mathrm{n}\end{array}$ \\
\hline & & $\mathbf{K}$ & Nomina & verba & Nomina \\
\hline \multirow{4}{*}{$\begin{array}{l}\text { Aku } \\
\text { mencubitnya }\end{array}$} & \multirow{4}{*}{ Kukuti'i } & $*$ & $k u-$ & 'kuti' ${ }^{9}$ & $-i$ \\
\hline & & $\mathbf{F}$ & $\begin{array}{l}\text { Penanda } \\
\text { Subjek }\end{array}$ & Predikat & $\begin{array}{l}\text { Penanda } \\
\text { objek }\end{array}$ \\
\hline & & $\mathbf{P}$ & Pelaku/actor & Tindakan & $\begin{array}{l}\text { Pasien/sasara } \\
\mathrm{n}\end{array}$ \\
\hline & & $\mathbf{K}$ & Nomina & verba & Nomina \\
\hline
\end{tabular}

Dalam bahasa Tolaki, klausa yang ada pada kata polisintesis memiliki bentuk deklaratif, interogatif dan imperatif. Ini dapat dilihat pada kata-kata berikut ini, yakni:

- Imperatif

- Basa'i! 'baca'

Basa

$+-i$

'Baca'

'itu'

Predikat

penanda objek

Tindakan sasaran/pasien

Verba transitif

demonstratif nomina dan pronominal

${ }^{9}$ berasal dari kata 'monggukuti' 
- Paka'iro! 'beri mereka makan'

$\begin{array}{ll}\text { paka'i } & + \text {-iro } \\ \text { 'beri makan' } & \text { 'mereka' } \\ \text { Predikat } & \text { penanda objek } \\ \text { Tindakan } & \text { sasaran/pasien } \\ \text { Verba transitif } & \text { demonstratif pronominal }\end{array}$

- Deklaratif

- Kupodea'ika 'saya juga mendengarnya'

$\begin{array}{lllr}k u-+ & \text { podea } & +-i & -+k a \\ \text { 'saya' } & \text { 'mendengar' } & \text { 'itu' } & \text { 'juga' } \\ \text { Penanda subjek } & \text { predikat } & \text { penanda objek } & \text { penanda ket. } \\ \text { Pelaku/agen } & \text { tindakan } & \text { sasaran } & \text { adjunct } \\ \text { Nomina } & \text { verba } & \text { nomina } & \text { afirmasi }\end{array}$

- Kuposaruke 'saya meminjamkan kepadanya'

\begin{tabular}{lll} 
Ku- + & posaru & \multicolumn{1}{c}{$+-k e$} \\
'saya' & 'meminjamkan' $\quad$ 'dia' \\
Penanda subjek & predikat & penanda objek \\
pelaku/agen & tindakan & sasaran/pasien \\
nomina & verba & pronomina 3 tunggal
\end{tabular}

- Norabu'i 'dia mencabutnya'

$\begin{array}{lll}\text { No- }+ & \text { rabu }^{10} & +-i \\ \text { 'dia' } & \text { 'mencabut' } & \text { 'itu' } \\ \text { Penanda subjek } & \text { predikat } & \text { penanda objek } \\ \text { pelaku/agen } & \text { tindakan } & \text { sasaran/pasien } \\ \text { pronomina 3 tunggal } & \text { verba } & \text { nomina }\end{array}$

- Interogatif ${ }^{11}$

- Ari'ito? 'Apakah sudah selesai'

$\begin{array}{lll}\text { Ari } & +-i-+ & +- \text { to } \\ \text { Sudah/selesai } & \text { itu } & \text { 'apakah' } \\ \text { Predikat } & \text { penanda objek } & \text { penanda interogatif } \\ \text { Tindakan } & \text { sasaran/pasien } & \text { penanda tanya } \\ \text { Kata kerja bantu } & \text { nomina } & \text { pronomina interogatif }\end{array}$

- Kurabu'i? 'Apakah harus saya cabut'

$\begin{array}{lll}K u-+ & r a b u & +-i \\ \text { 'saya' } & \text { 'cabut' } & \text { 'itu' } \\ \text { Penanda subjek } & \text { predikat } & \text { penanda objek }\end{array}$

${ }^{10}$ Kata 'rabu' dalam bentuk aktif morabu dalam bentuk pasif nirabu. Dengan demikian, kata 'rabu' adalah morfem dasar dalam verba 'cabut'

${ }^{11}$ Penanda interogatif didasarkan pada nada saat berujar ataupun tanda baca. 
LINGUA, Vol. 14, No. 2, September 2017

p ISSN: 1979 9411; e ISSN: 2442 238X

Http://lingua.pusatbahasa.or.id; Email: presslingua@gmail.com

Center of Language and Culture Studies, Surakarta, Indonesia

Pehala, Askul Ilfan. 2017. Frase dan Klausa dalam

Kata Polisintesis pada Bahasa Tolaki. Lingua (2017), 14(2): 127 140.

$\begin{array}{lll}\text { pelaku/agen } & \text { tindakan } & \text { sasaran/pasien } \\ \text { pronomina } 1 \text { tunggal } & \text { verba } & \text { nomina }\end{array}$

Mengenai frasa yang ada dalam kata polisintetis, frasa yang bisa terlihat dalam polisintesis pada bahasa Tolaki kebanyakan adalah frasa determiner dimana determiner itu sendiri berperan sebagai complement dan modifier saja utamanya . Ini dapat dilihat pada frasa berikut dimana kebanyakan bentuk kepunyaan atau 'possesive adjective atau genitive' terdapat dalam kata berpolisintesis di bawah ini dimana penandanya selalu melekat pada nomina. Hal ini bisa dilihat secara detail berdasarkan konstruksi pohon dari kata ini sendiri berdasarkan unsur konstituennya.

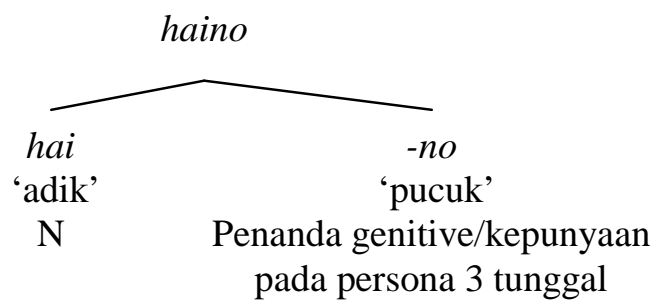

Gambar 2. Konstruksi frasa dalam kata polisintesis berdasarkan konstituen morfem penyusun kata

Sementara untuk frasa lain, sejauh penulis melihat, tidak mengalami kasus polisintesis. Berikut adalah sebagian kecil kata-kata polisintesis yang memiliki makna dalam bentuk frasa determiner yakni pu'uno 'pucuknya'; haino 'adiknya', padenggu 'parangku; amaro 'bapak mereka'; batuamu 'maksudmu'.

\section{SIMPULAN}

Polisintesis memang ada namun bahasa Tolaki adalah bahasa aglutinatif seperti bahasa Austronesia pada umumnya bukan inkorporatif. Berdasarkan analisis struktur dan pembentuk kata polisintesis atau segmentasi konstituennya, terlihat bahwa kata polisintesis dalam fungsi frasal hanya ada dalam lingkaran frasa determiner dengan ciri utama genitive sebagai modifier. Untuk klausa, kata polisintesis dapat berada dalam lingkaran verbal dan nominal serta terdapat klausa bercirikan deklaratif, imperatif dan interogatif. Dari segi fungsinya, klausa yang ada dalam kata polisintesis berpola SPOK, SPO, SP atau PO; peran berupa pelaku, tindakan dan sasaran; dan kategori berupa nomina, verba, pronomina ataupun demonstratif. Polisintesis dalam bahasa Tolaki ini terjadi disebabkan adanya perubahan atau pelesapan unsur-unsur fonem dalam kata yang menyisakan fonem asal dimana ada kecenderungan para penutur dalam melakukan pelesapan dan perubahan yang umumnya adalah morfemis adalah untuk perimbangan atau efisiensi dalam bertutur sehingga lidah mereka tidak mengeluarkan tuturan secara bertele-tele. 
LINGUA, Vol. 14, No. 2, September 2017

p ISSN: 1979 9411; e ISSN: 2442 238X

Http://lingua.pusatbahasa.or.id; Email: presslingua@gmail.com

Center of Language and Culture Studies, Surakarta, Indonesia

Pehala, Askul Ilfan. 2017. Frase dan Klausa dalam

Kata Polisintesis pada Bahasa Tolaki. Lingua (2017), 14(2): 127 140.

\section{DAFTAR PUSTAKA}

Br. Surbakti, Ernawati. (2012). Tipologi Sintaksis Bahasa Karo. Jurnal dalam Telangkai Bahasa dan Sastra, Januari 2012, 55-73 Tahun ke-6 N0.1. ISSN 1978-8266.

Carnie, Andrew. (2002). Syntax: A Generative Introduction. Cornwall: T.J. International Ltd.

Edwards, Owen. (2012). Grammatical Functions in Tolaki. Australia: The Australian National University. (Mimetograf).

Huang, Yan. (2007). Pragmatics. New York: Oxford University Press.

Keraf, Gorys. (1990). Linguistik Bandingan Tipologis. Jakarta: PT. Gramedia.

Kridalaksana, Harimurti. (1982). Kamus Linguistik. Jakarta: PT. Gramedia.

Matthews, P. H. (1981). Syntax. Avon: The Bath Press.

Parera, J.D. (1991). Historis Komparatif dan Tipologi Struktural. Jakarta: Penerbit Erlangga.

Putrayasa, Ida Bagus. (2014). Analisis Kalimat: Fungsi, Kategori dan Peran. Bandung: PT. Refika Aditama.

Sportiche, Dominique. et.al, (2014). An Introduction to Syntactic Analysis and Theory. West Sussex: Wiley Blackwell. 
LINGUA, Vol. 14, No. 2, September 2017

p ISSN: 1979 9411; e ISSN: 2442 238X

Http://lingua.pusatbahasa.or.id; Email: presslingua@gmail.com

Center of Language and Culture Studies, Surakarta, Indonesia

Pehala, Askul Ilfan. 2017. Frase dan Klausa dalam

Kata Polisintesis pada Bahasa Tolaki. Lingua (2017), 14(2): 127 140. 